\title{
METHOD OF SURGICAL TREATMENT OF CHRONIC DACRYOCYSTITIS AND ITS EFFECTIVENESS IN MONITORING PATIENTS IN THE EARLY POSTOPER- ATIVE PERIOD
}

\section{Zabolotnyi, O. Minaiev}

The aim. To develop a method for endonasal endoscopic dacryocystorhinostomy (EEDCR) and evaluate its effectiveness in monitoring patients in the early postoperative period.

Materials and methods. The study group (1st group) consisted of 45 patients with chronic dacryocystitis (CD), who underwent EEDCR according to the developed method, the comparison group (2nd group) included 36 patients who, after performing the developed EEDCR, an implant was installed in the dacryorhinostoma zone. The control group (3rd group) included 28 patients who underwent EEDCR according to the generally accepted method. Patients of groups 1 and 2 were divided into 2 subgroups: $1 A$ and $2 A$ included patients who underwent computed tomography of the lacrimal ducts in the preoperative period according to the developed method, and patients of subgroups $1 B$ and $2 B-a c-$ cording to the traditional algorithm. Reliably the best results of restoring lacrimation function were in subgroups $1 \mathrm{~A}$ and $1 \mathrm{~B}$ already from the 3rd day of observation after surgery, as well as in the subsequent periods of observation. The worst values of lacrimation function were recorded in the control clinical group with a statistically significant difference from other groups $(p<0.05)$. When comparing the results of treatment of subgroups $1 A$ with $1 B$ and $2 A$ with $2 B$, the best indicators were observed in subgroups $1 \mathrm{~A}$ and $2 \mathrm{~A}$, but due to the small sample of patients, statistical significance in the differences could not be achieved ( $p>0.05)$.

Results. A method of EEDCR has been developed, a comparative analysis of groups of patients according to the above indicators has been performed when observing patients in the early postoperative period. On the first day after surgery, the mean score of the severity of lacrimation according to the Munk scale significantly decreased in all groups and gradually decreased on the 7 th day and after 2 weeks $(p<0.05)$. Significantly better indicators were in subgroups $1 \mathrm{~A}$ and $1 B$ in the entire early postoperative period $(p<0.05)$. The degree of edema of the mucosa of the dacryorhinostoma zone and the middle nasal meatus at all periods of observation was the lowest in subgroup 1A from 3rd day and in each subsequent period of observation with a statistically significant difference from other groups $(p<0.05)$. On the 7 th day, significantly more patients with mucous discharge in the area of dacryorhinostoma and middle nasal meatus were observed in subgroup $2 B$ and in 3rd group $(p<0.05)$, and significantly better results were noted in subgroup $1 A$, where more than 2/3 patients had no mucous discharge. Reliably the best results of restoring lacrimation function were in subgroups $1 \mathrm{~A}$ and $1 \mathrm{~B}$ already from the 3rd day of observation after surgery, as well as in the subsequent periods of observation. The worst values of lacrimation function were recorded in the control clinical group with a statistically significant difference from other groups $(p<0.05)$. When comparing the results of treatment of subgroups $1 A$ with $1 B$ and $2 \mathrm{~A}$ with $2 \mathrm{~B}$, the best indicators were observed in subgroups $1 \mathrm{~A}$ and $2 \mathrm{~A}$, but due to the small sample of patients, statistical significance in the differences could not be achieved ( $p>0.05)$.

Conclusions. The developed EEDCR method complies with the principles of sparing surgery, is effective in the treatment of patients with $C D$, while there is a faster rate of recovery of the lacrimal function and mucosa, improves the quality of life of patients

Keywords: chronic dacryocystitis, treatment efficiency, endonasal endoscopic dacryocystorhinostomy, early postoperative period

Copyright (C) 2021, D. Zabolotnyi, O. Minaiev.

This is an open access article under the CC BY license (http://creativecommons.org/licenses/by/4.0).

\section{Introduction}

Chronic dacryocystitis (CD) accounts for a significant proportion of tear duct (TD) disease. Even in remission, this pathology is a threat to the eye due to the fact that in the lumen of the lacrimal sac in CD there is always a certain amount of pathogenic microorganisms that enter the conjunctiva. In addition, persistent tearing limits the ability to work in many professions, can lead to severe complications and disability [1].

Despite significant advances in science and technology, effective treatment of pathology of the vertical TD remains an urgent problem of modern ophthalmology and rhinology. There are two options for restoring tearing: conservative and surgical. Many groups of authors hold the opinion that conservative treatment is unpromising and does not justify itself: probing, bouching, rinsing and drug therapy have a temporary and unstable effect, and numerous manipulations in TD can lead to perforation of their walls, granulation and structures $[2,3]$.

The common treatment for $\mathrm{CD}$ is surgery [3]. Currently, the following methods are used: transcanalicular, with external and endonasal access to the lacrimal sac, each has many modifications, has its advantages and disadvantages. However, endonasal dacryocystorhinos- 
tomy has a number of undeniable advantages: no cosmetic defect, relatively short duration of operation, anatomical features and anomalies of intranasal structures are taken into account and, if necessary, their simultaneous correction is carried out, short postoperative period with much less pain syndrome $[2,4,5]$.

The question of the use of lacrimal implants in dacryocystorhinostomy is ambiguous. A number of authors consider intubation of TD as one of the important and obligatory components of effective treatment and prevention of recurrences of $\mathrm{CD}[6,7]$. The opposite opinion is based on the lack of difference in the effectiveness of treatment of this disease [8-10]. In addition, during the stay of the implant in the lumen of the TD there is a high level of complications, despite the use of bioinert materials such as silicone, propylene, polyurethane, etc. $[2,11,12]$. Biofilms can also form on the surface of the conductor and, accordingly, be a long-term cause of the inflammatory process in TD. In addition, the outer part of the lacrimal conductor is an aesthetic "defect", limits the patient's daily activities, reduces satisfaction with this treatment and impairs quality of life.

Another important and topical issue discussed among scientists and researchers is the options for plastic formation of dacryorhinostoma. Some authors believe that the cut flaps of the mucous membrane of the lateral wall of the nasal cavity and the medial wall of the lacrimal sac, and then their plastic placement in the area of dacryorhinostoma increase the effectiveness of surgical treatment of $\mathrm{CD}$, covering the exposed bone with these flaps reduces the risk of growth of granulation and then scar tissue, promotes faster epithelialization [6, 13, 14]. However, when cutting and plastic laying of these rags there are a number of negative moments influencing the final result: at the small sizes or the cicatricial changed, twisted lacrimal sac to form a flap from its medial wall it is difficult, high probability of mismatch of the shape of the cut flaps and their location in the area of dacryorhinostoma [15]. Therefore, opinions about the plastic laying or removal of the cut pieces of the lateral wall of the nasal cavity and the medial wall of the lacrimal sac in the world literature are quite ambiguous, and this problem remains unresolved.

Despite the existence of a large number of methods and modifications of surgical treatment of vertical TD obstruction, the search for the optimal one that would allow faster and better recovery of tear function and improve quality of life, would give a lower recurrence rate and complications remains relevant $[4,6,16]$.
The aim of the study was to develop a method of endonasal endoscopic dacryocystorhinostomy (EEDCR) and to evaluate its effectiveness in the observation of patients with $\mathrm{CD}$ in the early postoperative period.

\section{Materials and methods}

The study included 109 patients with $\mathrm{CD}$, who were examined and operated in the period 2004-2014 in the clinics of the Department of Otorhinolaryngology, Faculty of Internship and Postgraduate Education, Donetsk National Medical University of the Ministry of Health of Ukraine (ENT department of Institute of Emergency and Reconstructive Surgery of the Academy of Medical Sciences of Ukraine named after V. K. Husak and ENT department of Donetsk Road Clinical Hospital, Donetsk Railway State Enterprise). There were 86 women and 23 men aged 18 to 78 years (average, $49.1 \pm 16.2$ years).

All patients met the criteria for inclusion in the study, in all cases obtained voluntary consent for examination and treatment in accordance with the European Convention on Human Rights of 04.04.1997. The entire list of studies and methods of treatment used was approved by the Commission on Bioethics of the "Donetsk National Medical University named after M. Gorky of the Ministry of Health of Ukraine" (Donetsk, Ukraine), protocol No. 6 dated 24.06.2011 and the Commission on Bioethics of the Donetsk National Medical University of the Ministry of Health of Ukraine (Lyman, Donetsk region, Ukraine), protocol No. 26 from 15.12.2020.

The duration of complaints of tearing ranged from 2 months to 9 years. In $35(32.1 \%)$ patients CD was diagnosed for the first time, the duration of lacrimation in these patients was usually up to 1 year. In turn, 74 (67.9\%) patients had previously undergone many courses of conservative treatment by ophthalmologists in various combinations. They underwent tubing, drainage and/or washing, which then, in some cases, made it difficult to perform EEDCR due to severe scarring in the TD and the formation of "wrong stages" to them. This category of patients was disturbed by tearing, as a rule, for more than a year.

Previously, $61(56.0 \%)$ patients were treated by an otolaryngologist for various forms of chronic rhinitis, acute or chronic sinusitis, and $4(3.7 \%)$ of them had a history of endonasal surgery.

The above anamnesis data with the distribution of groups of patients are given in Table 1.

Table 1

History data in patients with $\mathrm{CD}$ with distribution by clinical groups

\begin{tabular}{|c|c|c|c|c|c|c|c|c|c|c|c|}
\hline \multirow{2}{*}{\multicolumn{2}{|c|}{ Anamnesis }} & \multicolumn{2}{|c|}{$\begin{array}{c}1 \mathrm{~A} \\
\mathrm{n}=28\end{array}$} & \multicolumn{2}{|c|}{$\begin{array}{c}1 \mathrm{~B} \\
\mathrm{n}=17\end{array}$} & \multicolumn{2}{|c|}{$\begin{array}{c}2 \mathrm{~A} \\
\mathrm{n}=21\end{array}$} & \multicolumn{2}{|c|}{$\frac{2 B}{n=15}$} & \multicolumn{2}{|c|}{$\begin{array}{c}3 \\
n=28\end{array}$} \\
\hline & & ahs & 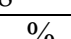 & ahs & $0 / 0$ & ahs & $0 / 4$ & ahs & $0 / 4$ & ahs & $0 /$ \\
\hline \multicolumn{2}{|l|}{ First diagnosed CD } & 9 & 32.1 & 5 & 29.4 & 7 & 33.3 & 5 & 33.3 & 9 & 321 \\
\hline \multirow{6}{*}{$\begin{array}{l}\text { Duration of com- } \\
\text { plaints of tearing }\end{array}$} & 2-6 months & 4 & 14.3 & 3 & 17.6 & 4 & 19 & 2 & 13.3 & 4 & 14,3 \\
\hline & $6-12$ months & 5 & 17.9 & 3 & 17.6 & 4 & 19 & 2 & 13.3 & 4 & 14,3 \\
\hline & $1-2$ years & 5 & 17.9 & 3 & 17.6 & 3 & 14.3 & 3 & 20 & 6 & 21.4 \\
\hline & $2-3$ years & 6 & 21.4 & 2 & 11.8 & 3 & 14.3 & 3 & 20 & 6 & 21.4 \\
\hline & $3-6$ years & 2 & 7.1 & 2 & 11.8 & 2 & 9.5 & 1 & 6.7 & 2 & 7.1 \\
\hline & $>6$ years & 6 & 21.4 & 4 & 23.5 & 5 & 23.8 & 4 & 26.7 & 6 & 21.4 \\
\hline \multicolumn{2}{|c|}{ History of rhinosinusitis } & 16 & 57.1 & 9 & 52.9 & 12 & 57.1 & 8 & 53.3 & 16 & 57.1 \\
\hline \multicolumn{2}{|c|}{ History of endonasal surgery } & 1 & 3.6 & 1 & 5.9 & 1 & 4.8 & 0 & 0 & 1 & 3.6 \\
\hline
\end{tabular}


As can be seen from the data in tab. 1, the indicators were evenly distributed among all groups and there was no statistically significant difference between the groups $(p<0.05)$. It should be noted that a large category consisted of patients who were bothered by tearing for more than 3 years, and whose $\mathrm{CD}$ was in remission for a long time or patients refused timely medical care.

All patients were restored to tear by performing EEDCR, all patients at this time had CD in remission.

Depending on the modification in which EEDCR was performed, all patients were divided into 3 groups: the 1st group (study) consisted of 45 patients to whom EEDCR was performed according to the method developed by us. The 2nd (comparison group) included 36 patients who, after performing the EEDCR developed by us, had a PVC conductor installed in the dacryorhinostoma area. The 3rd (control) group included 28 patients (archival material), which EEDCR was performed according to the traditional method: with preservation and plastic stacking of the cut flaps of the mucous membrane of the nasal cavity and lacrimal sac and with the installation of PVC conductor.

Depending on the variant of computed tomography (CT) TD patients of the 1 st and 2 nd groups were divided into 2 subgroups: subgroups $1 \mathrm{~A}$ and $2 \mathrm{~A}$ included patients who underwent contrast-enhanced CT TD in the preoperative examination according to the method developed by us $[17,18]$, subgroups $1 \mathrm{~B}$ and $2 \mathrm{~B}$ consisted of patients who underwent CT TD according to the traditional algorithm. In turn, patients of the control clinical group underwent dacryocystography in the preoperative examination, and to clarify the condition of the intranasal structures - CT of the paranasal sinuses.

In the early postoperative period, all patients were observed in hospital and on an outpatient basis. Tampons were removed from the nasal cavity for 1-2 days after surgery. In patients of the 2 nd and 3rd clinical groups, the conductor was removed from the lacrimal ducts after 1.5 months. All patients were performed daily sparing toilet of the nasal cavity, instructed on self-care of the nasal cavity. Medical support of patients of all groups was standard and included antibacterial drugs (systemic and local), antihistamines, irrigation therapy (saline solutions, topical steroids).

Patients in the study clinical group at each visit during the first month, the lacrimal ducts were washed with antiseptic solutions. Patients in the control clinical group and the comparison group were recommended to instill solutions of antiseptics for the entire period of the implant in TD.

The severity of lacrimation and lacrimation were assessed by testing according to the P. L. Munk scale on the 1st, 7th and 14th day after surgery. To do this, patients were asked to determine its intensity (Table 2).

Among the objective indicators in the terms of the 3 rd, 7th, 10th day and 2 weeks after the operation were studied the condition of the mucous membrane in the area of dacryorhinostoma and the middle nasal passage during endorhinoscopy. To do this, we assessed the degree of visualization of dacryorhinostoma, the presence of mucous secretions in patients and the degree of swelling of the mucous membrane according to the criteria of the modified Lund and Kennedy scale to assess the con- dition of the nasal mucosa after endonasal interventions (where 0 degree -1 sign and no sign expressed insignificantly, the 2nd degree - the sign is expressed moderately and the 3rd degree - the sign is expressed considerably). Among the functional parameters was determined by the function of tear removal by improved color tear breakdown by West under endoscopic control.

Table 2

Tear severity scale on the Munk scale

\begin{tabular}{|c|l|}
\hline Points & \multicolumn{1}{c|}{ Munk scale } \\
\hline 0 & No tearing \\
\hline 1 & $\begin{array}{l}\text { Tearing that requires drench less than twice a } \\
\text { day }\end{array}$ \\
\hline 2 & Tearing that requires drench $2-4$ times a day \\
\hline 3 & Tearing that requires drench 5-10 times a day \\
\hline 4 & $\begin{array}{l}\text { Tearing that requires drench more than 10 } \\
\text { times a day }\end{array}$ \\
\hline 5 & Constant tearing \\
\hline
\end{tabular}

To assess the statistical significance of differences between the study groups when comparing frequencies in independent groups used the criterion $\chi^{2}$ and Fisher's exact test, for frequencies in repeated measurements Cochran's Q criterion, to compare absolute values in repeated measurements - Friedman's test. Differences were considered statistically significant at a significance level of less than $5 \%(\mathrm{p}<0.05)$. The data in the tables are given in absolute (abs.), percentage (\%), average values with standard deviation (Mean \pm SD). Statistical analysis was performed using the licensed program MedCalc (MedCalc Software bvba, Ostend, Belgium; 2017).

\section{Research results}

Our method of EEDCR ("Method of endonasal endoscopic surgical treatment of chronic purulent dacryocystitis", Ukrainian patent for a utility model No. 53616 from 11.10.2010, bul. No. 19/2010) was as follows (Fig. 1). Karl Storz video endoscopic equipment, $4 \mathrm{~mm}$ rigid endoscopes with a viewing angle of $0^{\circ}, 30^{\circ}$ and $70^{\circ}$, a straight-tipped drilling machine, a set of forceps for endoscopic rhinosurgery, conical probes of various diameters and blunt-tipped needles for the lacrimal ducts. General anesthesia was supplemented with local application (sol. Lidocaine $10 \%$ ) and infiltration (sol. Lidocaine $2 \%$ ) anesthesia with anemia of the nasal mucosa of decongestants. In the first stage, the middle nasal cavity was medialized, thereby expanding the middle nasal passage. Next, diaphanoscopy was performed to identify the immediate incision site of the mucosa (Fig. 1, a). To do this, the fiber was tightly pressed to the medial corner of the eye, while the endoscope light was turned off for 10-15 seconds. A spot of light appears on the monitor screen, the site of the greatest glow during endoscopy, which corresponds to the lacrimal fossa and also to the lacrimal sac, where the bone wall has the smallest thickness. In the projection of the lower pole of the lacrimal sac with a sickleshaped scalpel cut out a U-shaped flap of mucous membrane measuring $10 \times 8 \mathrm{~mm}$, the base of which was behind (Fig. 1, b). The lateral wall of the nasal cavity in the area of the lacrimal bone and the frontal process of 
the upper jaw was exposed. A control diaphanoscopy was then performed to identify the location of the trepanation.

In the second stage, a boron with a straight tip and an aggressive nozzle formed a bone window in the area of the lower pole of the lacrimal sac, usually with a diameter of $8-10 \mathrm{~mm}$. At the end of this stage of the operation, the exposed medial wall of the lacrimal sac and the area of the bone that covers it on the periphery are clearly visible.

In the third stage, the Bowman's probe was inserted through the lower lacrimal point into the lower lacrimal duct and conducted to the medial wall of the bag. The tip of the probe rested against the wall of the lacrimal sac from the inside. The medial wall of the lacrimal sac was well contoured and protruded into the nasal cavity. After exposing the lacrimal sac, it was cut with a sickle-shaped scalpel along its entire length along a U-shaped trajectory (Fig. 1, c) to the bottom (maximum downwards), so that there was no threshold (pocket) in which tears could accumulate and fester. With the help of a bit- er, the mucous flaps of the medial wall of the lacrimal sac and the lateral wall of the nasal cavity were removed (Fig. 1, c), so that there were no excessive folds in the transport of tears. An important step is to open the lacrimal sac to its lower parts to ensure a uniform and unobstructed passage of the tear. Otherwise, the presence of a deepening in the lower parts of the lacrimal sac may contribute to stagnation and suppuration of tears, and subsequently - the emergence of granulations and scars, thereby causing a recurrence of $\mathrm{CD}$ (Fig. 1, d).

Next, the contents of the lacrimal sac were evacuated and the lacrimal ducts were washed with antiseptic solutions using a blunt-tipped ophthalmic needle or catheter passed through the lower lacrimal point. The operation was completed by inserting a finger tampon into the area of the dacryorhinostoma and the middle nasal passage. The next day, the tampon was removed.

The effectiveness of treatment in the early postoperative period was evaluated by subjective and objective indicators. Data on the severity of lacrimation are given in Table 3.

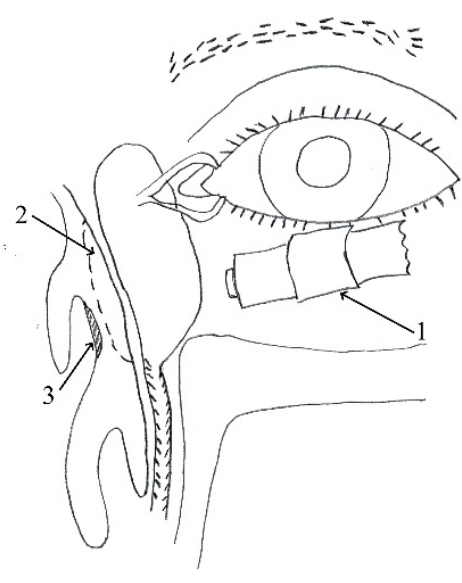

$a$

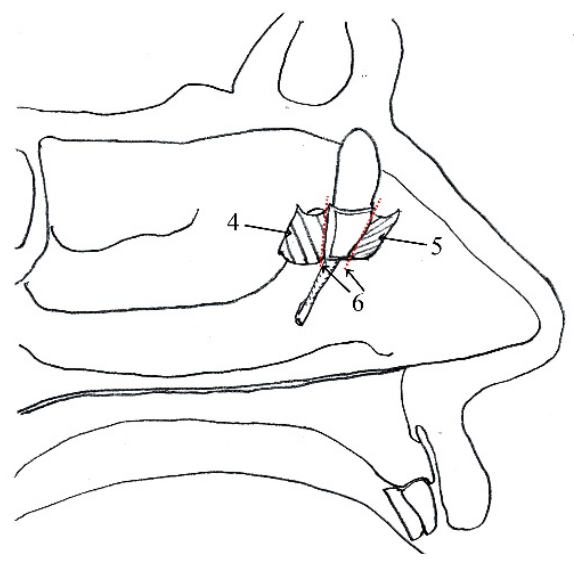

$c$

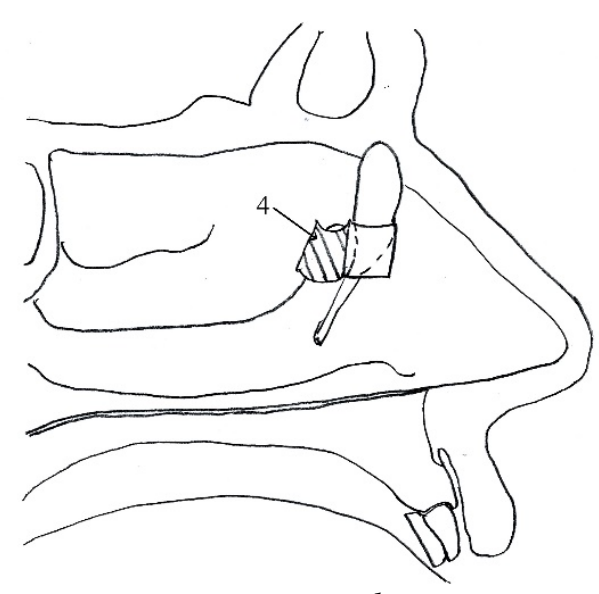

$b$

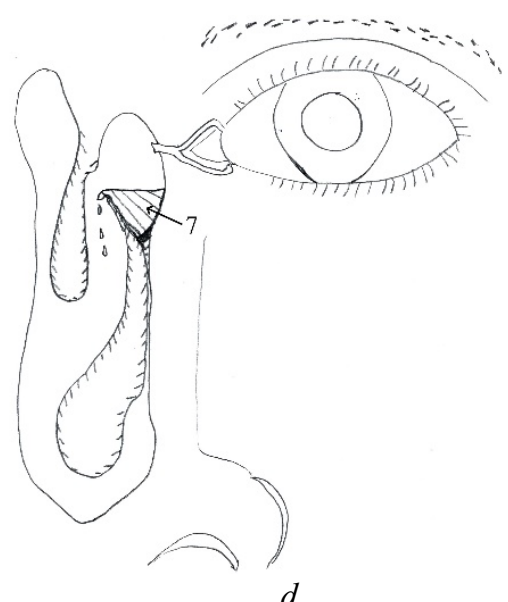

$d$

Fig. 1. The scheme of EEDCR stages according to the proposed method:

a - determination of the "optimal" incision site of the mucous membrane by means of diaphanoscopy

( 1 - light guide, 2 - projection of the lacrimal fossa, 3 - light spot);

$\mathrm{b}$ - allocation of the mucous flap in the projection of the bottom of the lacrimal sac

(4 - flap of the lateral wall of the nasal cavity);

$\mathrm{c}$ - opening of the lacrimal sac to the bottom, removal of mucous rags

(5 - flap of the medial saliva of the lacrimal sac, 6 - removal of mucous rags);

$d$ - stagnation of tears in the lower parts of the bag ( 7 - accumulation and suppuration of tears) 
The severity of tearing in patients with CD before treatment and in the early postoperative period according to testing on the Munk scale, the average score

\begin{tabular}{|c|c|c|c|c|c|}
\hline \multirow{2}{*}{ Period } & \multicolumn{5}{|c|}{ Group } \\
\cline { 2 - 6 } & $1 \mathrm{~A}$ & $1 \mathrm{~B}$ & $2 \mathrm{~A}$ & $2 \mathrm{~B}$ & 3 \\
\hline Before treatment & $3.46 \pm 0.69$ & $3.52 \pm 0.71$ & $3.57 \pm 0.67$ & $3.53 \pm 0.74$ & $3.42 \pm 0.69$ \\
\hline 1st day & $1.39 \pm 0.68^{2 \mathrm{~A} .2 \mathrm{~B} .3}$ & $1.47 \pm 0.71^{2 \mathrm{~A} .2 \mathrm{~B} .3}$ & $2.52 \pm 1.03^{1 \mathrm{~A} .1 \mathrm{~B}}$ & $2.6 \pm 1.05^{1 \mathrm{~A} .1 \mathrm{~B}}$ & $2.78 \pm 0.99^{1 \mathrm{~A} .1 \mathrm{~B}}$ \\
\hline 7th day & $1.10 \pm 0.73^{2 \mathrm{~A} .2 \mathrm{~B} .3}$ & $1.11 \pm 0.78^{2 \mathrm{~A} .2 \mathrm{~B} .3}$ & $2.09 \pm 1.04^{1 \mathrm{~A} .1 \mathrm{~B}}$ & $2.33 \pm 0.97^{1 \mathrm{~A} .1 \mathrm{~B}}$ & $2.5 \pm 0.92^{1 \mathrm{~A} .1 \mathrm{~B}}$ \\
\hline 14th day & $0.60 \pm 0.62^{2 \mathrm{~A} .2 \mathrm{~B} .3}$ & $0.88 \pm 0.69^{2 \mathrm{~B} .3}$ & $1.38 \pm 0.86^{1 \mathrm{~A}}$ & $1.53 \pm 1.06^{1 \mathrm{~A} .1 \mathrm{~B}}$ & $1.71 \pm 0.85^{1 \mathrm{~A} .1 \mathrm{~B}}$ \\
\hline
\end{tabular}

Note: $1 A$ - the difference is statistically significant in comparison with group $1 A, p<0.05 ; 1 B-$ the difference is statistically significant in comparison with group $1 B, p<0.05 ; 2 A$ - the difference is statistically significant in comparison with group $2 A$, $p<0.05$; $2 B$ - the difference is statistically significant in comparison with group $2 B, p<0.05 ; 3$ - the difference is statistically significant in comparison with group $3, p<0.05$

As can be seen from the Table 3 data, the average score of tearing on the Munk scale before treatment in patients of all groups was quite high and was more than 3.4. When compared between the groups there was no significant difference $(\mathrm{p}>0.05)$, the distribution was uniform. In all groups on the first day after surgery, the mean score decreased significantly (in each group with a statistically significant difference compared to pretreatment, $\mathrm{p}<0.05$ ) and gradually decreased in subsequent follow-up periods. Significantly better indicators were in subgroups $1 \mathrm{~A}$ and $1 \mathrm{~B}$ compared with subgroups $2 \mathrm{~A}, 2 \mathrm{~B}$ and group No. 3 in the entire early postoperative period $(\mathrm{p}<0.05)$, except for subgroups $1 \mathrm{~B}$ and $2 \mathrm{~A}$ in the observation period of 2 weeks, where the difference was not statistically significant $(\mathrm{p}>0.05)$. In the control clinical group, the mean score in these observation periods was the highest, but in comparison with subgroups $2 \mathrm{~A}$ and $2 \mathrm{~B}$ without a statistically significant difference $(\mathrm{p}>0.05)$.

Objective indicators of the condition of the mucous membrane of the dacryorhinostoma area and the middle nasal passage were also evaluated. The degree of edema of the middle nasal passage and dacryorhinostoma area in patients of all groups in the early postoperative period is shown in Fig. 2.

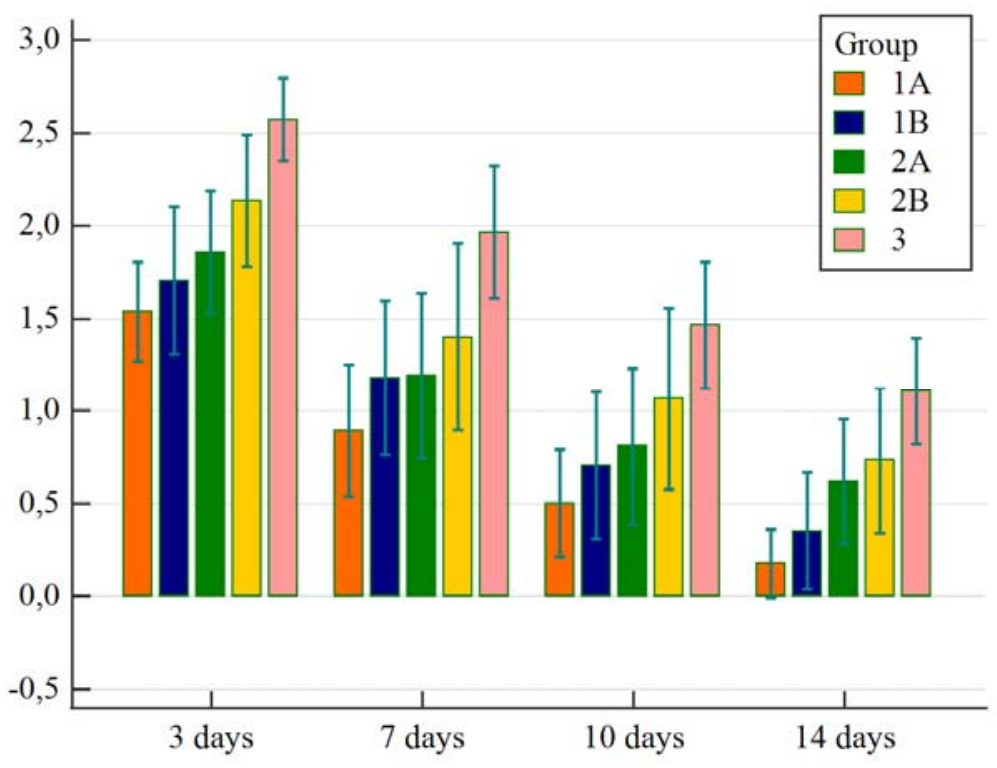

Fig. 2. The degree of edema of the middle nasal passage and dacryorhinostoma area in patients of all groups in the early postoperative period on the Lund and Kennedy scale (assessment of statistically significant differences between groups by criterion $\left.\chi^{2}, p<0.05\right)$

In all periods of observation of the early postoperative period, the degree of swelling of the mucous membrane of the dacryorhinostoma and middle nasal passage was the lowest in subgroup 1A from the 3rd day and in each subsequent observation period with a statistically significant difference from other groups $(p<0.05)$. When comparing these indicators of subgroup $1 \mathrm{~A}$ with $1 \mathrm{~B}$ and subgroup $2 \mathrm{~A}$ with $2 \mathrm{~B}$, they were better in subgroups $1 \mathrm{~A}$ and $2 \mathrm{~A}$ throughout the early postoperative period, but without a statistically significant difference $(p>0.05)$. In the 3rd group in all terms of observation of the early postoperative period this indicator had the greatest values with statistically significant difference from other groups $(\mathrm{p}<0.05)$.

Also, the condition of the mucous membrane of the dacryorhinostoma zone and the middle nasal passage was assessed by the presence of mucous secretions (Fig. 3). 


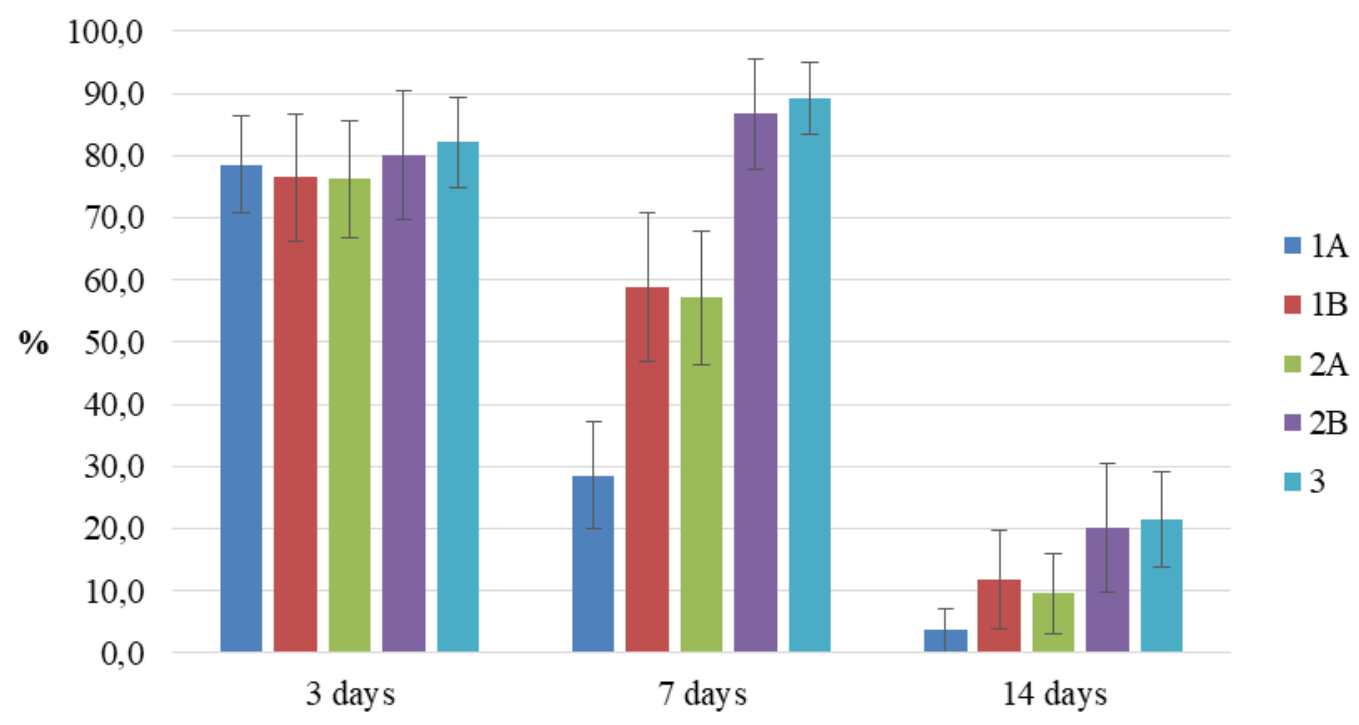

Fig. 3. Patients with mucous secretions in the area of dacryorhinostoma and in the middle nasal passage in the early postoperative period

As can be seen from the above data, on the $3 \mathrm{rd}$ day after surgery, the distribution of patients for the presence of mucous secretions among all groups was uniform, there was no statistically significant difference between the groups $(p>0.05)$. On the 7 th day, significantly more such patients were observed in subgroup $2 \mathrm{~B}$ and in group $3(\mathrm{p}<0.05)$, and significantly better results were observed in subgroup $1 \mathrm{~A}$, where more than $2 / 3$ of patients had no mucous secretions in the area dacryorhinostoma and middle nasal passage, the difference from other groups was statistically significant $(\mathrm{p}<0.05)$.

On the 10th day and 2 weeks after surgery, the percentage of patients with mucous secretions decreased significantly in all groups, the best results were observed in subgroup $1 \mathrm{~A}$, but a statistically significant difference was only when compared with the subjects of the $3 \mathrm{rd}$ group $(\mathrm{p}<0.05)$.

Endoscopic examination of the nasal cavity also assessed the degree of dacryorhinostoma imaging, guided by the following criteria: "well visualized", "reduced visualization" and "no clear visualization". It should be noted that throughout the early postoperative period of observation in all patients dacryorhinostoma was well visualized (Fig. 4).

Tearing function was also assessed as an objective indicator in the early postoperative period. To do this, we used an improved West color tear sample (sample with dye) with endoscopic control. The results were evaluated using the following criteria: positive ("+") - the dye is released from the rhinostoma into the nasal cavity within the first 5 minutes after instillation into the conjunctival cavity; slow (" \pm ") - the same, but after 6-20 minutes; negative ("-") - the same, but later than 20 minutes or not at all.

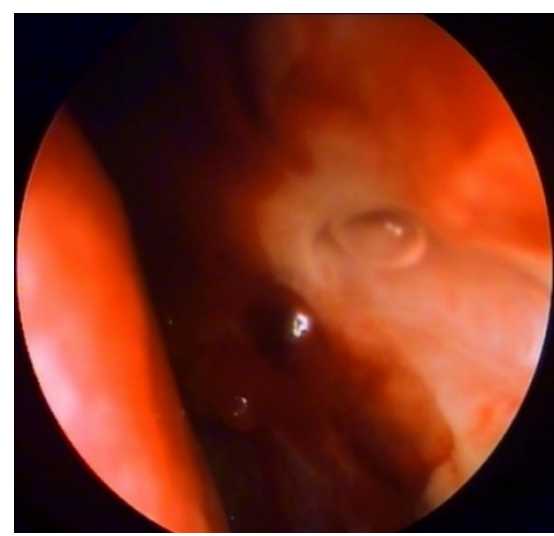

Fig. 4. Patient M., subgroup 1A, two weeks after surgery: the formed dacryorhinostoma is well visualized, there is a passage of tears with an air bubble as evidence of the

preserved function of tearing during blinking

The results of tear function in blinking in patients of all groups in the early postoperative period are shown in Fig. 5. It should be noted that before treatment in all patients the values of tear function were negative, and in the early postoperative period it was restored in all patients. Significantly better results were obtained in subgroups 1A and 1B from the 3rd day of observation after surgery, as well as in subsequent observation periods $(p<0.05)$. The worst values of tear function were recorded in the control clinical group with a statistically significant difference from other groups $(\mathrm{p}<0.05)$. When comparing the values of this function in subgroups $1 \mathrm{~A}$ with $1 \mathrm{~B}$ and in subgroups $2 \mathrm{~A}$ with $2 \mathrm{~B}$, the best results were in subgroups $1 \mathrm{~A}$ and $2 \mathrm{~A}$ throughout the early postoperative period, but without a statistically significant difference $(\mathrm{p}>0.05)$. 


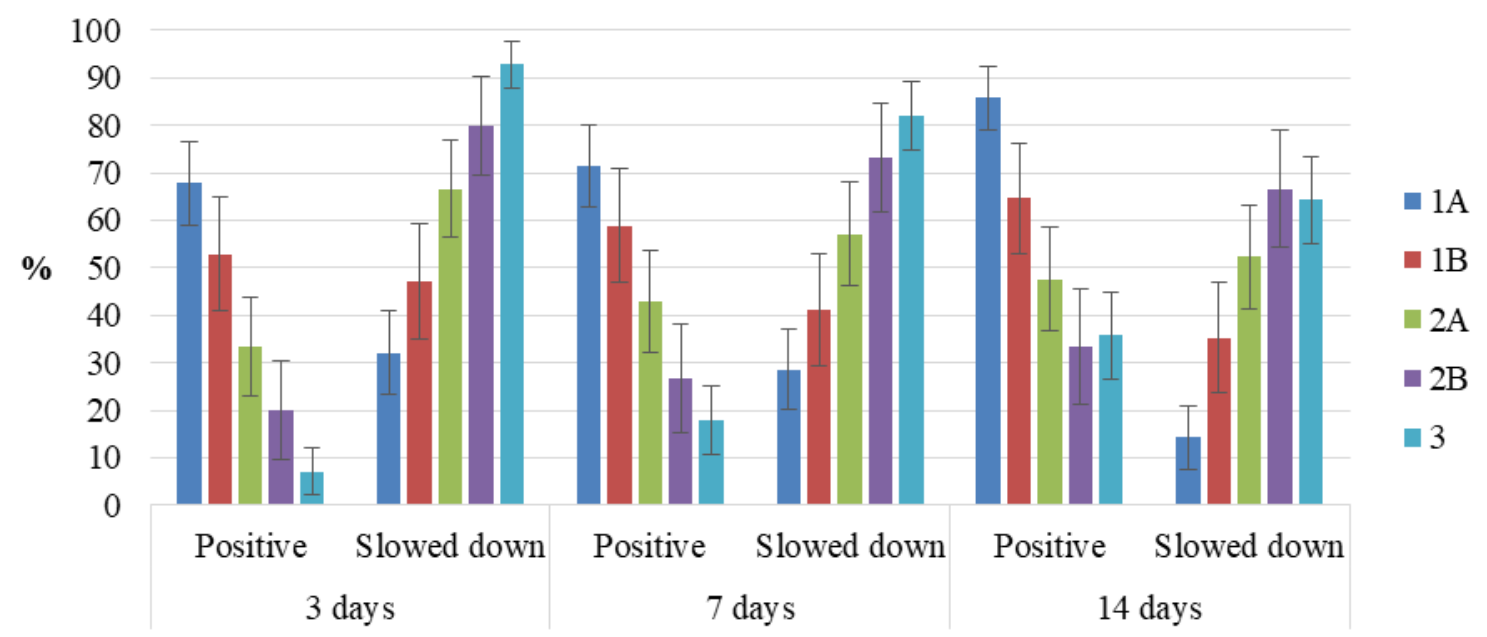

Fig. 5. The results of tear function when blinking on the 3rd, 7th day and 2 weeks after surgery in patients of all clinical groups

\section{Discussion of research results}

Recently, much attention has been paid to the study of the late postoperative period in patients after EEDCR, because it is during this period, as a rule, there is a recurrence of the disease and a significant reduction in quality of life. Many authors try to trace in detail the dynamics of this period, to identify and eliminate the factors that affect the recurrence of CD [19]. However, in our opinion, not enough attention is paid to the study of the peculiarities of the early postoperative period. In such works, scientists mostly demonstrate generalized data without a qualitative and quantitative description of the indicators being studied [20]. In our opinion, such indicators as the rate of recovery of tearing after surgery, as well as its degree and stability are of great importance for the patient and for his quality of life. In addition, if the values of tear function are slow, then such patients may be a "risk group" and need more attention and observation.

In our work when using the developed method of EEDCR in the treatment of patients with CD there are significantly better results of tear recovery in the subjective assessment of the severity of lacrimation on the Munk scale from the 1st day, and in objective determination of tear function according to the modified West tearnasal test - from the 3rd day of observation after surgery. Worse tear recovery were in the comparison group and in the control group, and were apparently associated with the presence of a conductor in the lumen of the common lacrimal duct and dacryorhinostoma. The implant somewhat fills the lumen of the TD and, thus, can impede the outflow of tears. In addition, as a foreign body in the conjunctival cavity, it can cause tear overproduction. In turn, in the control clinical group, the results were most likely due to the fact that in the area of dacryorhinostoma could prevent the outflow of tears in addition to the PVC conductor, and swollen displaced flaps of the mucous membrane of the lateral wall of the nasal cavity and medial wall of the lacrimal sac.

Based on the analysis of mucosal regeneration in the area of dacryorhinostoma and middle nasal passage, significantly better results in terms of mucosal edema in patients of the study group were from the 3rd day of observation, and in terms of mucus - from the 7 th day. The established PVC conductor had a certain role in mucus formation in the comparison group and the control group. The latter, like the foreign body of the TD and nasal cavity, provoked inflammatory changes, thereby stimulating the production of mucus and possibly tears.

It should be noted that when comparing the results of treatment of subgroups $1 \mathrm{~A}$ with $1 \mathrm{~B}$ and $2 \mathrm{~A}$ with $2 \mathrm{~B}$, the best indicators were observed where in the preoperative period CT was used according to the proposed method. But the differences between the groups were not statistically significant due to the small number of patients $(p>0.05)$.

Thus, the results of treatment of patients with CD in the early postoperative period show that the effectiveness of the developed EEDCR technique exceeds other modifications of this surgery, which use a conductor in $\mathrm{TD}$ and retain plastic mucous flaps.

The latter in our study had a negative effect on the rate of recovery of tearing and mucous membranes in the postoperative area. It should be noted that certain scientists in the study and comparison of modifications of the EEDCR significant advantages in the method of operation with the preservation of mucous flaps were not observed [19, 21].

Study limitations. Unfortunately, patients could not always correctly indicate the features of the anamnesis of their disease, such as its duration, details of previous treatment, and so on. This introduced some difficulties in data registration and analysis.

In addition, some patients showed dissatisfaction with the performance of medical and diagnostic procedures in the early postoperative period. However, such situations can be offset by clear explanatory work on the need for long-term monitoring and clear implementation of recommendations for a positive outcome.

Prospects for further research. It is necessary to further study with more patients to better analyze the statistical differences between the studied groups of patients, as well as to standardize the criteria for the effectiveness of surgical treatment: visual, functional and subjective, based on physical or psychological sensations of patients.

\section{Conclusions}

1. The application of the developed EEDCR method reduces the severity of lacrimation according to 
the Munk scale in 2 times from the 1st day after surgery and provides significantly better indicators of tear function throughout the early postoperative period in contrast to traditional surgical procedures.

2. The developed method of EEDCR corresponds to the principles of lean surgery, which promotes rapid recovery of the mucous membrane of the dacryorhinostoma and middle nasal passage on the 7 th day after surgery. The indicators of swelling of the mucous membrane and mucous secretions in patients of the study group were 2 times less than in patients of the control group.

3. The proposed method of EEDCR is effective in the treatment of patients with $C D$, with faster and significantly better rates of recovery of tear function from the 3rd day after surgery $(\mathrm{p}<0.05)$.

\section{Conflict of interests}

The authors declare that there is no conflict of interests.

\section{References}

1. McGrath, L. A., Satchi, K., McNab, A. A. (2018). Recognition and Management of Acute Dacryocystic Retention. Ophthalmic Plastic \& Reconstructive Surgery, 34 (4), 333-335. doi: http://doi.org/10.1097/iop.0000000000000982

2. Magomedov, M. M., Borisova, O. Y., Bakharev, A. V., Lapchenko, A. A., Magomedova, N. M., Gadua, N. T. (2018). The multidisciplinary approach to the diagnostics and surgical treatment of the lacrimal passages. Vestnik Otorinolaringologii, 83 (3), 88 93. doi: http://doi.org/10.17116/otorino201883388

3. Enright, N. J., Brown, S. J., Rouse, H. C., McNab, A. A., Hardy, T. G. (2019). Nasolacrimal Sac Diverticulum: A Case Series and Literature Review. Ophthalmic Plastic \& Reconstructive Surgery, 35 (1), 45-49. doi: http://doi.org/10.1097/iop.0000000000001156

4. Kumar, S., Mishra, A. K., Sethi, A., Mallick, A., Maggon, N., Sharma, H., Gupta, A. (2018). Comparing Outcomes of the Standard Technique of Endoscopic DCR with Its Modifications: A Retrospective Analysis. Otolaryngology-Head and Neck Surgery, 160 (2), 347-354. doi: http://doi.org/10.1177/0194599818813123

5. Li, E. Y., Wong, E. S., Wong, A. C., Yuen, H. K. (2017). Primary vs Secondary Endoscopic Dacryocystorhinostomy for Acute Dacryocystitis With Lacrimal Sac Abscess Formation: A Randomized Clinical Trial. JAMA Ophthalmol, 135 (12), $1361-$ 1366. doi: http://doi.org/10.1001/jamaophthalmol.2017.4798

6. Beloglazov, V. G., Atkova, E. L., Abdurakhmanov, G. A., Krakhovetskii, N. N. (2013). Prevention of ostial obstruction after microendoscopic endonasal dacryocystorhinostomy. Vestnik oftal'mologii, 129 (2), 19-22.

7. Wu, S., Xu, T., Fan, B., Xiao, D. (2017). Endoscopic dacryocystorhinostomy with an otologic T-type ventilation tube in repeated revision cases. BMC Ophthalmology, 17 (1). doi: http://doi.org/10.1186/s12886-017-0539-7

8. Pakdel, F. (2012). Silicone Intubation Does not Improve the Success of Dacryocystorhinostomy in Primary Acquired Nasolacrimal Duct Obstruction. Journal of Ophthalmic and Vision Research, 7 (3), 271-272.

9. Ananth, L., Hosamani, P., Chary, G. (2011). Efficacy of endonasal dacryocystorhinostomy, using "cold steel” instruments without stenting, in treatment of distal nasolacrimal duct obstruction. The Journal of Laryngology \& Otology, 125 (6), 590-594. doi: http://doi.org/10.1017/s002221511100017x

10. Chong, K. K. L., Lai, F. H. P., Ho, M., Luk, A., Wong, B. W., Young, A. (2013). Randomized Trial on Silicone Intubation in Endoscopic Mechanical Dacryocystorhinostomy (SEND) for Primary Nasolacrimal Duct Obstruction. Ophthalmology, 120 (10), 2139-2145. doi: http://doi.org/10.1016/j.ophtha.2013.02.036

10. Orlova, E. I., Davydov, D. V. (2017). Lacrimal stents in the lacrimal pathways' surgery. Ophthalmology Journal, 10 (4), 48-55. doi: http://doi.org/10.17816/ov10448-55

11. Meireles, M. N., Viveiros, M. M., Meneghin, R. L., Galindo-Ferreiro, A., Marques, M. E., Schellini, S. A. (2017). Dacryocystectomy as a treatment of chronic dacryocystitis in the elderly. Orbit, 36 (6), 419-421. doi: http://doi.org/10.1080/01676830.2017.1353111

12. Çukurova, I., Caner Mercan, G., Çetinkaya, E., Gümüsssoy, M., Söken, H. (2012). Endoscopic dacryocystorhinostomy: outcomes using mucosal flap preserving technique. European Archives of Oto-Rhino-Laryngology, 270 (5), 1661-1666. doi: http://doi.org/10.1007/s00405-012-2285-z

13. Mueller, S. K., Freitag, S. K., Lefebvre, D. R., Bleier, B. S. (2017). Endoscopic DCR using bipedicled interlacing mucosal flaps. The Laryngoscope, 128 (4), 794-797. doi: http://doi.org/10.1002/lary.26730

14. Wu, W., Cannon, P. S., Yan, W., Tu, Y., Selva, D., Qu, J. (2011). Effects of Merogel coverage on wound healing and ostial patency in endonasal endoscopic dacryocystorhinostomy for primary chronic dacryocystitis. Eye, 25 (6), 746-753. doi: http://doi.org/10.1038/eye.2011.44

15. Baek, J. S., Jeong, S. H., Lee, J. H., Choi, H. S., Kim, S. J., Jang, J. W. (2017). Cause and Management of Patients With Failed Endonasal Dacryocystorhinostomy. Clinical and Experimental Otorhinolaryngology, 10 (1), 85-90. doi: http://doi.org/10.21053/ceo.2016.00192

16. Zabolotnyi, D. I., Minaiev, O. O. (2020). Chronic dacryocystitis: Clinical and Radiological parallels. Scientific Collection «InterConf», 2 (38), 913-922. Available at: https://interconf.top/documents/2020.12.16-18.pdf

17. Minaiev, O. (2020). Preoperative radiological examination of patients with chronic dacryocystitis. Science Review, 8 (35), 22-28. doi: http://doi.org/10.31435/rsglobal_sr/30122020/7319

19. Green, R., Gohil, R., Ross, P. (2016). Mucosal and lacrimal flaps for endonasal dacryocystorhinostomy: a systematic review. Clinical Otolaryngology, 42 (3), 514-520. doi: http://doi.org/10.1111/coa.12754

20. Peng, W., Tan, B., Wang, Y., Wang, H., Wang, Z., Liang, X. (2017). A Modified Preserved Nasal and Lacrimal Flap Technique in Endoscopic Dacryocystorhinostomy. Scientific Reports, 7 (1). doi: http://doi.org/10.1038/s41598-017-07364-9

21. Ayoob, M., Mahida, K., Qurat-ul-ain, Q., Dawood, Z. (2013). Outcome and complications of endoscopic dacryocystorhinostomy without stenting. Pakistan Journal of Medical Sciences, 29 (5). doi: http://doi.org/10.12669/pjms.295.3393

Received date 24.11.2020

Accepted date 22.12.2020

Published date 30.01.2021

Dmytro Zabolotnyi, MD, Professor, Academician of National Academy of Medical Sciences of Ukraine, Director, State Institution «Kolomiychenko Institute of Otolaryngology of National Academy of Medical Sciences of Ukraine», Zoolohichna str., 3, Kyiv, Ukraine, 03680

E-mail: amtc@kndio.kiev.ua

Oleksii Minaiev, Assistant, Department of Surgery, Endoscopy, Otorhinolaryngology, Reconstructive Surgery and Radiation Diagnostics, Donetsk National Medical University of Ministry of Health of Ukraine, Pryvokzalna srt., 27, Lyman, Donetsk region, Ukraine, 84404

E-mail: dr.min.alex@gmail.com 